The meristematic zones of $C$. erecta y $E$. retusa, kept an important bank of dormant and viable buds, in the basal and medial zone of the axis after herbicide application, which means that the glyphosate do not reduce the ability of regrowth in these species.

According to these results, several morphological characters shared by the three species were recognized, which may play an important role in avoiding the herbicide action.

\title{
Caracterización molecular de integrones clase 1. Expresión y caracterización funcional de orfs asociados
}

\author{
Ayelén Patricia Porto \\ ayelenporto1@gmail.com \\ Dr. Gabriel Gutkind / Dr. José Di Conza \\ Cátedra de Microbiología General \\ Facultad de Bioquímica y Cs Biológicas \\ Universidad Nacional del Litoral \\ Fecha de la defensa: 18/03/2013
}

\section{Resumen}

La diseminación de determinantes de resistencia a antimicrobianos a través del intercambio de material genético entre las poblaciones bacterianas, y la posterior emergencia de microorganismos resistentes es un fenómeno actual y en crecimiento. Uno de los elementos involucrados en la integración y expresión de genes de resistencia a antimicrobianos son los integrones. Estos son elementos genéticos móviles que actúan como vectores naturales de clonado y expresión integrando y expresando genes en casete.

Como parte de un estudio epidemiológico de integrones realizado con anterioridad en nuestra región, se ha detectado en tres aislamientos multiresistentes de enterobacterias un nuevo gen en casete codificante para una $\beta$-lactamasa ( bla $_{\text {OXA-101 }}$ ) derivada de bla ${ }_{\text {OXA-10 }}$ localizado en un integrón clase 1. Las $\beta$-lactamasas de tipo OXA han sido descriptas en enterobacterias y en otros bacilos gram-negativos no fermentadores de glucosa (principalmente en Acinetobacter baumanii y Pseudomonas aeruginosa). Se hallan frecuentemente localizadas en plásmidos e integrones, asiduamente como genes en casete dentro de integrones clase 1.

Con relación a este tema, en éste trabajo de tesis se planteó el análisis de la localización y transferibilidad genética de bla ${ }_{\mathrm{OXA}-101}$, y el estudio de las características bioquímicas de la $\beta$-lactamasa. Los resultados obtenidos permiten afirmar que este gen en casete se encuentra localizado en un plásmido conjugativo de alto peso molecular. Se determinó además, el punto isoeléctrico y masa molecular de la enzima obtenida de forma recombinante. Respecto al espectro de hidrólisis, sólo se observó una disminución de la susceptibilidad a ampicilina y piperacilina netamente debido a OXA-101. Por último, se realizó una breve caracterización cinética de la misma.

Dentro de los integrones clase 1, existen los denominados integrones inusuales. Estos poseen como característica única la presencia de una región común (CR), que contiene el marco abierto de lectura orf513, codificante para una posible recombinasa de ADN. Se encuentra postulado que la proteína Orf513 podría estar involucrada 
tanto en el proceso de integración de genes (mayormente determinantes de resistencia a antibacterianos) originando los integrones inusuales, como en el de captura de genes cromosomales y posterior propagación de los mismos en elementos móviles. A través del alineamiento de secuencias CR con proteínas del grupo de IS91, fue observado que estas secuencias comparten características y motivos que permiten suponer que las CR son elementos transponibles de la familia de las secuencias de inserción IS91, por lo que se ha propuesto renombrarlas como secuencias de inserción CR (ISCR) $y$, puntualmente, a la CR asociada a integrones clase 1 inusuales: ISCR1. La característica distintiva de replicación por transposición en rolling circle de IS91 podría explicar los cambios estructurales observados en los integrones inusuales, ya que este mecanismo de replicación provee a estos elementos de la capacidad de movilizar secuencias adyacentes. Convenientemente, estos elementos ISCR1 proveen un promotor para la expresión de genes integrados corriente abajo de estos elementos, lo cual enfatiza la importancia de la presencia de estas secuencias en lo que a diseminación de la resistencia comprende.

En cuanto a este último tema se realizaron dos tipos de estudios:

En uno de ellos se analizó la presencia de integrones inusuales en aislamientos clínicos de enterobacterias recolectados en dos instituciones de salud de la ciudad de Santa Fe. En los integrones inusuales hallados se realizó la detección de determinantes de resistencia a quinolonas (genes qnr) y a $\beta$-lactámicos $\left(b / a_{\text {CTX-M-2 }}\right.$ y bla $\left.a_{\text {PER-2 }}\right)$. Finalmente, se efectuó la caracterización de ciertas regiones presentes en los integrones inusuales. La detección de integrones inusuales asociados a diferentes determinantes de resistencia afirma la importancia de la realización de estos estudios de manera periódica.

Por otro lado, se analizó la capacidad de interacción de Orf513 con diferentes secuencias de ADN, de manera de poder estudiar la hipótesis de que esta proteína posee actividad recombinasa y es capaz de movilizar genes contiguos al elemento ISCR1. En primer lugar, se realizaron diferentes estrategias de clonado y expresión con el fin de obtener la proteína Orf513 recombinante convenientemente pura. Posteriormente, se realizaron ensayos de retardo de movilidad electroforética entre el extracto con la proteína en estudio y diferentes secuencias de ADN, obteniéndose evidencias de interacción entre Orf513 y secuencias de ADN particulares. De nuestro conocimiento, esta es la primera descripción realizada de la actividad enzimática postulada para Orf513.

\section{Molecular characterization of class 1 integrons. Associated orfs expression and functional characterization}

\section{Summary}

As part of an epidemiological study previously conducted in our region it has been detected a new gene cassette coding for a $\beta$-lactamase $\left(b / a_{\text {OXA-101 }}\right)$ derived from bla ${ }_{\mathrm{OXA}-10}$, located in a class 1 integron in three multidrug resistant isolates of Enterobacteriaceae. In this study, we have characterized the genetic localization and transferability of bla $_{\text {OxA-101 }}$, and also the biochemical characteristics of this $\beta$-lactamase. The obtained results confirm that this gene cassette is located on to a high molecular weight conjugative plasmid. Also, it was determined the isoelectric point and molecular weight of the 
purified recombinant enzyme. Finally, a brief kinetic characterization was performed.

The presence of complex class 1 integrons in clinical isolates of Enterobacteriaceae collected in two health institutions in Santa Fe city was analyzed. In the complex integrons detected, the existence of quinolone resistance determinants (qnr genes) and $\beta$-lactams (bla CTX-M-2 $_{\text {a }}$ and bla ${ }_{\text {PER-2 }}$ ) was studied. Finally, molecular characterization of certain regions of complex class 1 integrons was carried out.

We examined the occurrence of protein-
DNA interaction between Orf513 and different DNA sequences, so as to examine the hypothesis that this protein has recombinase activity and is able to mobilize adjacent genes to ISCR1 element. Electrophoresis mobility shifts assays were performed between the protein extract, containing Orf513, and several DNA sequences. The obtained data showed DNA-binding activity for a purified extract of Orf513 on particular DNA sequences. To the best of our knowledge, this is the first experimental description related to the proposed enzymatic activity for this protein.

\section{Efecto de metales pesados y plaguicidas sobre organismos planctónicos de diferente nivel trófico y eficiencia de acumulación por microalgas}

\section{Luciana Regaldo}

Iregaldo@fhuc.unl.edu.ar /

luregaldo@gmail.com.

Dr. Horacio Troiani

Dra. Ana María Gagneten

Laboratorio de Ecotoxicología

Facultad de Humanidades y Ciencias

Universidad Nacional del Litoral.

Centro Atómico Bariloche. Comisión Nacional de Energía Atómica. Avenida Bustillo Km 9,5, CP 8400, San Carlos de Bariloche, Río Negro, Argentina.

Laboratorio de Ecotoxicología. Departamento de Ciencias Naturales

Facultad de Humanidades y Ciencias

Universidad Nacional del Litoral.

Fecha de la defensa: 02/12/2013

\section{Resumen}

En este trabajo se abordó la contaminación por microcontaminantes inorgáni- cos (Cromo, Cobre, Plomo y Arsénico) y plaguicidas (Atrazina -Atr-y Endosulfán -End-) en ecosistemas acuáticos continentales y su efecto sobre organismos planctónicos de diferente nivel trófico productores y consumidores primarios-. así como la eficiencia de acumulación por microalgas a escala de laboratorio.

Se realizaron muestreos mensuales durante un año (2011-2012) en cuatro sitios del sistema de los arroyos Colastiné-Corralito, que atraviesan zonas agrícolas e industriales del centro-sur de la provincia de Santa Fe (Argentina). Se midieron variables fisicoquímicas in situ y en laboratorio, además se determinaron las concentraciones de metales pesados y arsénico en agua y sedimento y plaguicidas en agua. Se analizó la posible vinculación entre la contaminación por metales pesados, arsénico y plaguicidas registrada en agua y sedimento 